\title{
AVALIAÇÃO DO GRAU DE IMPLEMENTAÇÃO DA CONSTRUÇÃO ENXUTA EM TRÊS EMPRESAS CONSTRUTORAS GOIANAS
}

\author{
Assessment of the degree of Lean Construction implementation in three \\ construction companies in Goiás
}

\author{
Tatiana Gondim do Amaral ${ }^{1}$, Pedro Henrique Ferreira Candido ${ }^{2}$, Gabriel Abdala Vieira Di Coimbra ${ }^{3}$, \\ Carlos Augusto Bouhid de Camargo Filho ${ }^{4}$
}

Recebido em 15 de fevereiro de 2017; aceito em 22 de setembro de 2017; disponível on-line em 07 de novembro de 2017.

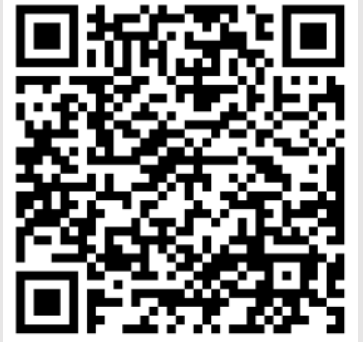

PALAVRAS CHAVE:

Produção enxuta; Construção enxuta; Grau de implementação; Construção civil; Métodos de avaliação.

\section{KEYWORDS:}

Lean production, Lean construction, Implementation degree; Civil construction; Assessment method.

\footnotetext{
* Contato com os autores:
}

${ }^{1}$ e-mail: tatiana_amaral@hotmail.com ( T. G. Amaral )

Professora Doutora da Escola de Engenharia Civil e Ambiental da Universidade Federal de Goiás - UFG.

${ }^{2}$ e-mail: pedro.93hfc@gmail.com (P. H. F. Candido)

Escola de Engenharia Civil e Ambiental da Universidade Federal de Goiás - UFG.

${ }^{3}$ e-mail: gabriel_abdala_@hotmail.com (G.A. V. Di Coimbra )

Escola de Engenharia Civil e Ambiental da Universidade Federal de Goiás - UFG.

${ }^{4}$ e-mail: carlos_bouhid@hotmail.com (C. A. B. Camargo Filho)

Mestrando do Programa de Pós Graduação em Estruturas, Geotecnia e Construção Civil - GECON da Universidade Federal de Goiás UFG.
ABSTRACT: Lean production is a production model that aims to reduce wastes in that heen studied for more than on increasing companies in the State of Goias. The existing categories (the current safety legislation and/or global average above 1.8. It is important to highlight the need for changes in the questionnaire, aiming at reducing it in order to reduce the time of application. It could be systems of quality management and work safety. In the final version of the questionnaire it is suggested a reformulation so that only items directly linked to Lean Construction and not contemplated by these systems are considered. 


\section{INTRODUÇÃO}

No contexto econômico atual, de retração da economia brasileira, a indústria da construção civil é um dos principais setores a sofrer com reduções de demanda e investimentos. 0 setor já tem uma queda no ano, potencializada pelo atraso nos pagamentos das obras executadas pelo governo federal, aumento de impostos e alta da inflação (CBIC, 2016).

Neste cenário, surge a necessidade de as construtoras buscarem formas de aumentarem sua capacidade produtiva, ao mesmo tempo em que se reduzem perdas, visando, como fim, uma diminuição nos custos de produção envolvidos. Em conjunto a estes fatores, ainda é necessário melhorar a qualidade do produto final da empresa, para atender às necessidades dos clientes. Desta maneira, a Produção Enxuta tornou-se uma alternativa para o setor (ETGES, 2012).

Baseada no Sistema Toyota de Produção (STP), desenvolvido no Japão na década de 50 , a Produção Enxuta busca otimizar o desempenho da produção. Seu objetivo é atender com perfeição a requisitos e necessidades específicos de seus consumidores, por meio de objetivos e técnicas aplicados ao longo da linha de produção, visando ainda reduzir ao máximo as perdas presentes no processo (HOWELL, 1999).

No entanto, como este sistema produtivo é aplicado na manufatura, é necessária uma adaptação de seus conceitos, que foi iniciada com o trabalho de Koskela (1992), cunhando o termo Construção Enxuta, e sua aplicação norteada por um conjunto de princípios e ferramentas, que vêm sendo desenvolvidos e inovados desde então (ETGES, 2012).

Embora Koskela (1992) tenha apresentado seus princípios de maneira didática, facilitando seu entendimento, estes não possuem uma independência ou diferenciação clara entre si. Essa dependência atrapalha a identificação dos princípios da Construção Enxuta que estão sendo usados no canteiro de obras e sua relação com a teoria estudada. Consequentemente, torna-se difícil avaliar a implementação do pensamento Lean nesse contexto.

Ainda que a Construção Enxuta nunca tenha se consolidado no Brasil como uma filosofia disseminada entre as empresas (CARVALHO, 2008), a estagnação econômica, vivenciada no cenário atual, favorece a implantação de novos modelos de gestão, como uma forma de diferenciação da concorrência e de se atingir metas de qualidade e sustentabilidade (CARVALHO, 2008).

Atualmente, existem diversos autores que já desenvolveram metodologias para a avaliação da implementação destes conceitos. Porém, a quantidade de trabalhos neste âmbito, embora crescente nos últimos anos, ainda é muito pequena quando comparada ao que ocorre em outros ramos da manufatura, que possuem uma diversidade de abordagens metodológicas maior (CAMARGO FILHO, 2017).

Diante do exposto o presente trabalho busca validar uma ferramenta que avalia o grau de implementação da construção enxuta em empresas construtoras e identificar o nível de conhecimento das construtoras participantes em relação aos princípios Lean.

Este trabalho possui importância no sentido de utilizar e validar uma ferramenta que busca, além de diagnosticar a presença deste modelo de gestão em empresas construtoras, refinar o processo avaliativo em si. Esta ferramenta irá ajudar empresas a identificar quais práticas da filosofia enxuta estão sendo aplicadas com maior eficácia, assim como aquelas que não estão obtendo desempenho satisfatório, facilitando a implementação deste sistema ou a simples melhoria na eficiência e desempenho dessas empresas.

\subsection{OBJETIVOS}

O objetivo desta pesquisa consiste em aplicar e validar o questionário desenvolvido por Camargo Filho (2017), com o intuito de avaliar o 
grau de implementação da construção enxuta em empresas construtoras.

Pretende-se, também, identificar o nível de conhecimento das empresas participantes da pesquisa, em relação à Construção Enxuta, e despertar o interesse para a implementação de seus princípios no canteiro de obra, além de, diagnosticar a presença da filosofia Enxuta em três empresas construtoras atuantes na região metropolitana de Goiânia.

\section{REVISÃO BIBLIOGRÁFICA}

\subsection{PRODUÇÃO ENXUTA}

A Produção Enxuta tem suas raízes no Sistema Toyota de Produção, criado pela Toyota Motor Corporation no final dos anos 1940 e desenvolvido nas décadas seguintes. O método utilizado pela companhia era diferente do vigente à época, de produção em massa, introduzido pela Ford no início do século XX, e era baseado em duas novas teorias: o Just-in-Time (JIT) e o Total Quality Control (TQC). O primeiro, característica inerente à Produção Enxuta, se resume em produzir bens e serviços exatamente no momento em que serão necessários, eliminando a necessidade de estoques (BALLARD; HOWELL, 1995). Já o TQC é uma filosofia que tem como objetivo garantir a qualidade $e$ melhoria contínua dos produtos e sistemas de uma organização. É um controle de qualidade que envolve todos os trabalhadores, departamentos e operações realizadas pela empresa (SOARES, 1998; KOSKELA 1992).

\subsubsection{Princípios do Pensamento Enxuto}

Womack e Jones (1998) estabeleceram cinco princípios fundamentais para o Lean Thinking (Pensamento Enxuto). O Primeiro deles, valor, é definido pelo cliente final, e é o que sustenta qualquer empresa a longo prazo. No Lean Thinking, o foco principal é identificar o valor do produto e aumentá-lo de maneira sistemática, considerando requisitos de clientes específicos, e sendo necessária uma tentativa consciente de definição de valor para sua aplicação (JUNQUEIRA, 2006).

Ainda segundo esse autor, o próximo princípio seria o Fluxo de Valor ou Cadeira de Valor, que são as ações necessárias para se levar um produto a passar pelas três tarefas gerenciais críticas: solução de problemas, gerenciamento da informação e transformação física. Nesta etapa de definição de Cadeia de Valor, podem ser identificadas etapas em que se agrega valor ao produto e desperdícios mais urgentes.

O terceiro princípio é o Fluxo. Após as análises anteriores, criar o fluxo é fazer com que as etapas em questão fluam. Nas atividades industriais, este foi primeiramente introduzido por Ford em suas linhas de montagem. No Japão, a partir de 1940, o conceito de fluxo contínuo foi desenvolvido, havendo uma grande preocupação com a redução da variabilidade na linha de produção, menor lead time (tempo que o produto leva para atravessar todo o fluxo de produção) e diminuição dos desperdícios no processo (KOSKELA, 2000).

Há ainda nestes princípios o conceito de Produção Puxada, que espera que o cliente faça o pedido e gere uma demanda específica, "puxe o produto", ao invés de empurrá-lo ao mercado. Isso se torna possível graças à redução no tempo de concepção dos produtos gerada pela introdução do fluxo contínuo no processo. Com o menor lead time, a empresa consegue atender o cliente de forma eficiente e permitir que a própria demanda puxe sua produção (JUNQUEIRA, 2006).

Existe, por fim, o princípio de Perfeição, que consiste em manter as etapas anteriores sempre em funcionamento, garantindo uma interação entre elas e promovendo uma melhoria contínua nos processos da empresa (JUNQUEIRA, 2006). Essa melhoria contínua é um fundamental componente das filosofias TQC e JIT e visa o esforço da redução de perdas e aumento do valor na gestão, envolvendo todas as pessoas participantes do processo. Para realizá-la, é necessária uma definição clara de prioridades e 
metas, padronização de procedimentos, identificação das causas reais dos problemas e implementação das respectivas ações corretivas (BARROS, 2005).

\subsection{CONSTRUÇÃO ENXUTA}

\subsubsection{Modelo de Gestão Tradicional}

Segundo Koskela (1992), o conceito mais geral relacionado à construção é de um conjunto de atividades baseado em um modelo de conversão simples, ilustrado na Figura 1, em que há entrada de materiais e serviços e saída de um produto acabado, através do chamado processo de produção. Esse modelo assume que todo o processo produtivo pode ser dividido em subprocessos e que cada um deles pode ser realizado e analisado de maneira independente.

O custo total do processo, e por consequência o preço do produto final, relacionase aos custos de cada um dos subprocessos, da mão-de-obra e dos materiais. O princípio de valor não é relevante neste modelo tradicional (ao contrário do modelo enxuto que foca no cliente) e está ligado principalmente à qualidade do produto em si e do seu processo produtivo.

No entanto, Formoso (2002) ressalta que existem algumas deficiências importantes nesse tipo de conversão. Primeiramente, não são considerados fluxos físicos como transporte, espera de materiais e retrabalhos nessa análise; e na construção civil essas atividades originam uma grande parcela do custo do processo. Segundo o autor, uma otimização focada em subprocessos específicos dificilmente resultará em uma melhoria do sistema de produção como um todo. Por último, não considerar requisitos de clientes, mesmo em uma produção com grande eficiência, pode gerar produtos inadequados e com baixo valor de mercado.

\subsubsection{Modelo de Gestão Enxuto}

O modelo enxuto (Figura 2) é definido como um fluxo de materiais e/ou informações por toda a etapa de processamento. Koskela (1992) adicionou as atividades de espera, inspeção e transporte ao sistema de conversão tradicional e criou um modelo que, segundo ele, cobre todos os aspectos mais importantes da produção.

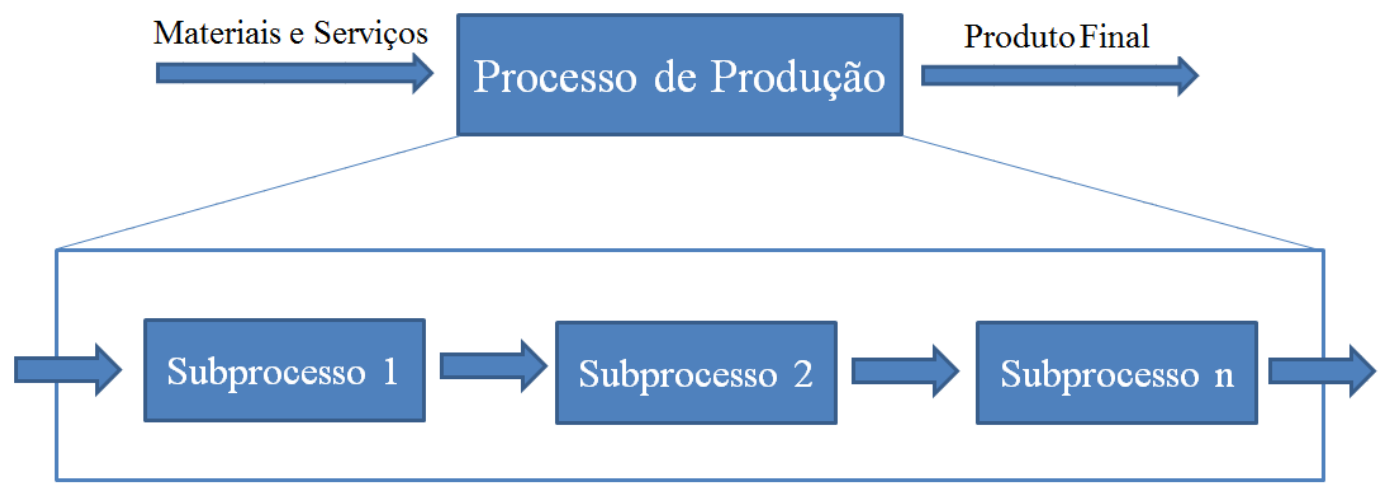

FIGURA 1: Modelo de conversão tradicional. FONTE: Koskela (1992). 


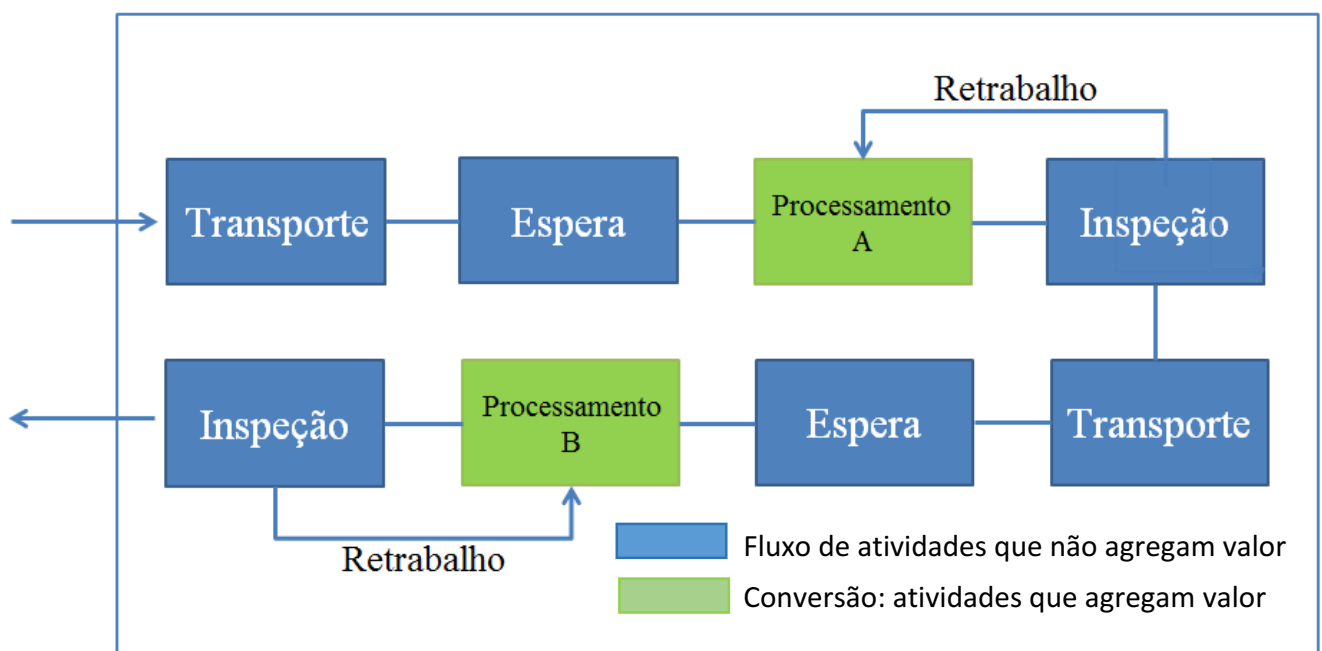

FIGURA 2: Modelo de conversão proposto por Koskela. FONTE: Koskela (1992).

As atividades adicionadas são referidas como de fluxo, e ao contrário das atividades de conversão (processamentos), não agregam valor ao produto, que neste modelo se refere ao cumprimento de requisitos de clientes. Formoso (2002) ainda complementa afirmando que, mesmo em orçamentos de construções que utilizam sistemas tradicionais de produção, há atividades de fluxo implícitas, e é exatamente sua falta de transparência que dificulta sua percepção e prejudica a gestão da produção.

\section{METODOLOGIA}

\subsection{CLASSIFICAÇÃO DA PESQUISA}

A pesquisa é classificada quanto à abordagem como qualitativa e quantitativa, realizada por meio de um estudo de caso, no qual avaliou-se o grau de implementação das práticas lean em três empresas construtoras do estado de Goiás.

Quanto à natureza, trata-se de uma pesquisa aplicada, já que tem por objetivo final a produção de conhecimento a ser utilizado na construção civil.

Ainda, quanto aos objetivos e procedimentos, a pesquisa é classificada como exploratória, tendo em vista que, a partir de um vasto levantamento bibliográfico e posterior coleta de dados, realizou-se um estudo de caso a fim de compreender de maneira mais aprofundada o problema em questão.

\subsection{ETAPAS DA PESQUISA}

O estudo foi realizado baseado nas seguintes etapas:

a. Definição de critérios para seleção e caracterização das empresas e dos empreendimentos, nos quais foi aplicado o questionário;

b. Estudo do questionário para avaliar o grau de implantação da construção enxuta nas construtoras goianas;

c. Aplicação do questionário proposto por Camargo Filho (2017);

d. Análise dos resultados obtidos propondo-se a melhoria da ferramenta de aplicação.

\subsubsection{Definição de critérios para seleção e caracterização das empresas}

As empresas foram selecionadas levando em consideração os seguintes critérios:

- Interesse em participar da pesquisa;

- Tempo de atuação na área de construção civil;

- Que possuísse empreendimentos diferenciados tecnologicamente em sua execução e no mercado Goiano;

- Que possuísse Sistema de Gestão da Qualidade e/ou Ambiental ou uma gestão estruturada dos seus processos;

- Que possuísse uma logística e distribuição 
de suprimentos racionalizada;

- Participantes dos encontros da Comunidade da Construção ${ }^{1}$.

Vale ressaltar que foi adotada uma amostragem não probabilística intencional, em que o pesquisador utiliza os membros mais acessíveis da população para retirar sua amostra para estudos.

\subsubsection{Caracterização das empresas}

Os dados foram coletados no ato da entrevista com os representantes das empresas, porém a identidade das empresas não foi divulgada na pesquisa a fim de manter o anonimato e preservar a imagem das três empresas participantes, denominada na pesquisa em A, B e C.

As empresas participantes da pesquisa são construtoras e incorporadoras certificadas pela ISO 9001 e PBPQ-H.

Em relação a empreendimentos executados, a empresa ' $\mathrm{B}$ ' estava com seis obras simultâneas em andamento, enquanto as empresas 'A' e 'C' estavam com apenas um empreendimento. Quanto à implantação da Construção Enxuta, apenas a empresa ' $B$ ' declarou implantar a filosofia.

As empresas ' $A$ ' e ' $B$ ' detêm mais de 30 anos de atuação no mercado goiano, já a empresa ' $C$ ' pouco mais de 10 anos (Quadro 1 ).

\subsubsection{Questionário de avaliação}

O questionário foi desenvolvido com objetivo de fornecer informações quanto a presença de práticas lean nas construtoras participantes, ajudando a identificar problemas e oportunidades de melhorias em seu produto na busca da satisfação de seus clientes e colaboradores.

O Formulário é composto por 98 práticas retiradas das literaturas, e foram divididas em 10 categorias para facilitar a aplicação e a coleta das fontes de evidências. Cada prática é acompanhada por suas respectivas fontes de evidência e referências bibliográficas, assim como o princípio da produção enxuta e o vínculo conceitual entre o princípio e a prática.

As fontes de evidência tratam-se de comprovações a serem colhidas para a averiguação da presença ou não de cada prática. Elas direcionaram o aplicador e o entrevistado no que deveria ser encontrado para considerar as práticas aplicadas, não aplicadas ou parcialmente aplicadas, de acordo com a escala de avaliação estipulada.

\begin{tabular}{|c|c|c|c|c|c|c|}
\hline EMPRESA & PORTE & CERTIFICAÇÕES & $\begin{array}{c}\text { QUANTO } \\
\text { TEMPO POSSUI } \\
\text { CERTIFICAÇÃO }\end{array}$ & $\begin{array}{c}\text { ÁREA } \\
\text { CONSTRUÍDA } \\
\left(\mathrm{M}^{2}\right)\end{array}$ & $\begin{array}{c}\text { DECLARA APLICA A } \\
\text { CONSTRUÇÃO } \\
\text { ENXUTA }\end{array}$ & $\begin{array}{l}\text { QUANTIDADE } \\
\text { DE OBRAS } \\
\text { EM } \\
\text { ANDAMENTO }\end{array}$ \\
\hline A & Médio & $\begin{array}{l}\text { ISO } 9001 \text { e } \\
\text { PBQP-H nível A }\end{array}$ & 16 anos & $\begin{array}{c}\text { Mais de } \\
700.000,00\end{array}$ & Não & 1 \\
\hline B & Grande & $\begin{array}{l}\text { ISO } 9001 \text { e } \\
\text { PBQP-H nível A }\end{array}$ & 15 anos & $\begin{array}{c}\text { Mais de } \\
700.500,00\end{array}$ & Sim & 6 \\
\hline C & Médio & $\begin{array}{l}\text { ISO } 9001 \text { e } \\
\text { PBQP-H nível A }\end{array}$ & 6 anos & $\begin{array}{c}\text { Mais de } \\
90.000,00\end{array}$ & Não & 1 \\
\hline
\end{tabular}

\footnotetext{
${ }^{1}$ A Comunidade da Construção trata-se de um movimento de âmbito nacional que visa à integração dos agentes da cadeia produtiva com o intuito de aprimorar os sistemas construtivos e difundir o conhecimento através de melhores práticas.
} 
As categorias foram elaboradas através de um levantamento de artigos do International Group for Lean Construction (IGLC) no decorrer de 17 anos de pesquisas, onde foram analisadas as palavraschaves nos conceitos e práticas da Lean Construction determinando 84 grupos que deram origem, inicialmente, a 14 categorias. Posteriormente, em uma pesquisa realizada por Camargo Filho (2017), notou-se a necessidade de resumir as categorias para facilitar a aplicação do formulário. Ao final do estudo, ele reduziu as 14 categorias em 10, como ilustrado na Tabela 1.

A cada item do formulário foi atribuída uma escala de avaliação que varia de 0 a 3 , estabelecendo quatro níveis diferentes de classificação. Estas notas foram estipuladas por meio da análise das fontes de evidências e entrevistas realizadas com os funcionários da empresa a fim de abordar diferentes pontos de vista sobre a execução das práticas no canteiro de obra.

Os requisitos para o fornecimento das notas estão descritos no Quadro 1.

\subsubsection{Aplicação do Formulário}

A fase de aplicação do questionário foi dividida pelos aplicadores em duas etapas. A primeira consistiu em aplicar o formulário no escritório ou sede da empresa com o objetivo de avaliar, principalmente, a categoria de Gerenciamento de Projetos e Desenvolvimentos de Produtos. Esta abordou a forma que a empresa idealiza e projeta o produto para ter uma boa aceitação de mercado e atender às necessidades exigidas pelos seus clientes.

A segunda parte consistiu na aplicação do questionário em um dos empreendimentos que está sendo executado pela empresa. Trata-se principalmente de analisar o canteiro de obra em busca das fontes de evidências exigidas no estudo para a validação das práticas na cadeia de produção da construtora e notar os benefícios inseridos na cadeia produtiva devido à utilização de práticas do pensamento enxuto. Em todos as empresas a pesquisa foi respondida pelo engenheiro gestor da obra em conjunto a um responsável da implantação do Sistema de Gestão de Qualidade. Na empresa B além desses dois responsáveis estava também presente o técnico de segurança.

TABELA 1: Categorias finais do formulário.

\begin{tabular}{clc} 
SIGLA & \multicolumn{1}{c}{ Categoria } & Número de práticas \\
\hline GQ & Gestão da Qualidade & 12 \\
\hline GC & Gestão de Custo & 6 \\
\hline ST & Segurança do Trabalho & 5 \\
\hline GV & Gerenciamento Visual & 8 \\
\hline MC & Melhoria contínua & 6 \\
\hline TI & Tecnologia da Informação e Comunicação & 5 \\
\hline RH & Recursos Humanos & 7 \\
\hline LOG & Logísticos e Gerenciamentos da Cadeia de Suprimentos & 16 \\
\hline GP & Gerenciamento de Projetos e Desenvolvimento do Produto & 11 \\
\hline PCP & Planejamento e Controle da Produção & 22 \\
\hline
\end{tabular}




\begin{tabular}{|c|l|}
\hline \multicolumn{2}{|c|}{ QUADRO 1: Escala de avaliação das práticas lean. } \\
\hline Notas & \multicolumn{1}{c|}{ Requisitos } \\
\hline $\mathbf{3}$ & Prática totalmente aplicada e efetiva. \\
\hline $\mathbf{2}$ & Prática aplicada parcialmente, há inconsistência em sua aplicação. \\
\hline $\mathbf{1}$ & Prática é conhecida e a empresa pretende aplicar no canteiro. \\
\hline $\mathbf{0}$ & Prática não aplicável. \\
\hline
\end{tabular}

FONTE: Adaptação de Etges (2012).

\subsubsection{Análise dos resultados e alterações no questionário}

Após a aplicação do formulário e avaliação de todas as práticas na empresa, o resultado proveniente das entrevistas foi computado em um formulário. Neste formulário, cada prática recebeu a nota atribuída na avaliação para assim poder gerar os resultados gráficos para melhor análise da pesquisa. Esta análise foi realizada através de utilização de tabelas interativas do programa Microsoft Excel ${ }^{\circledR}$.

Como resultados gráficos do estudo realizado, tem-se o histograma das práticas, com a distribuição das frequências de ocorrência de cada nota, por empresa. Além disso, foi feita a elaboração de um gráfico Radar, a fim de mostrar a média aritmética das notas para cada categoria e para o questionário como um todo, também por empresa.

Os resultados obtidos serão discutidos e analisados, buscando desenvolver uma ferramenta de fácil aplicação que minimize a necessidade de um conhecimento aprofundado do assunto para realizar a avaliação.

\section{ANÁLISE DE DADOS E DISCUSSÃO DE RESULTADOS}

O questionário foi aplicado a um empreendimento de cada construtora, por acreditar que os resultados são da empresa e a comprovação das práticas pode ser identificada na gestão dos processos relacionados às categorias determinadas nessa pesquisa.

\subsection{MÉDIAS GLOBAIS DAS CATEGORIAS POR EMPRESA}

A Figura 3 compara as médias obtidas em cada uma das categorias por empresa. Como pode ser observado, não houve grandes disparidades entre as notas globais, apenas em práticas específicas, as quais serão discutidas posteriormente. As siglas utilizadas seguem as definições estabelecidas na Tabela 1.

Com essas médias, foi possível fazer uma análise da presença da construção enxuta nessas empresas.

$\mathrm{Na}$ Figura 4 apresentam-se as disposições das variâncias das notas obtidas por categorias. As siglas utilizadas seguem as definições estabelecidas na Tabela 1.

Pode-se observar que apenas na categoria Controle de Custo houve disparidade entre as variâncias. Nas demais categorias, houve uma similaridade entre as notas obtidas nas práticas de cada empresa.

Como já informado anteriormente, somente a empresa ' $B$ ' afirmou implantar a Construção Enxuta, porém esta não se destacou com relação às outras, conforme ilustrado na Figura 5. 
- Empresa $\mathrm{A}=$ Empresa B $=$ Empresa C

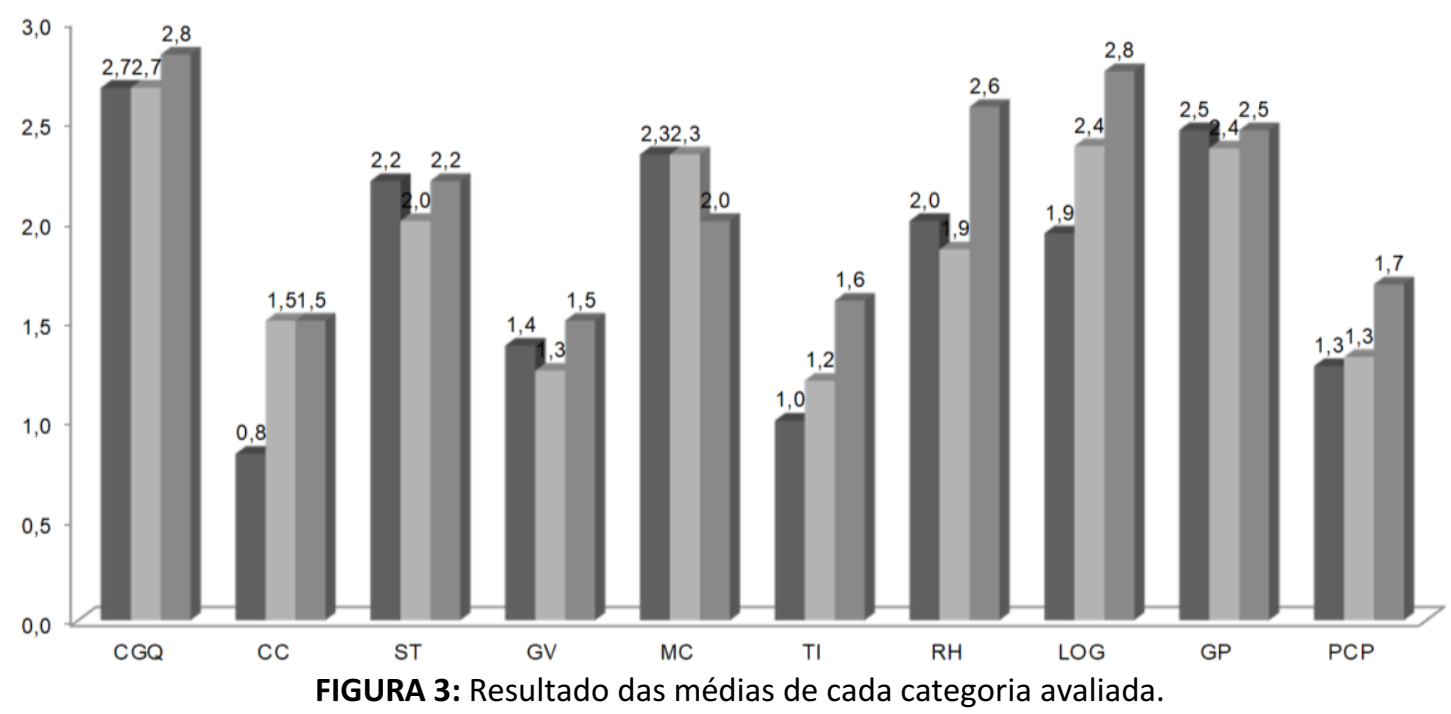

FONTE: Autoria própria.

- Empresa A =Empresa B =Empresa C

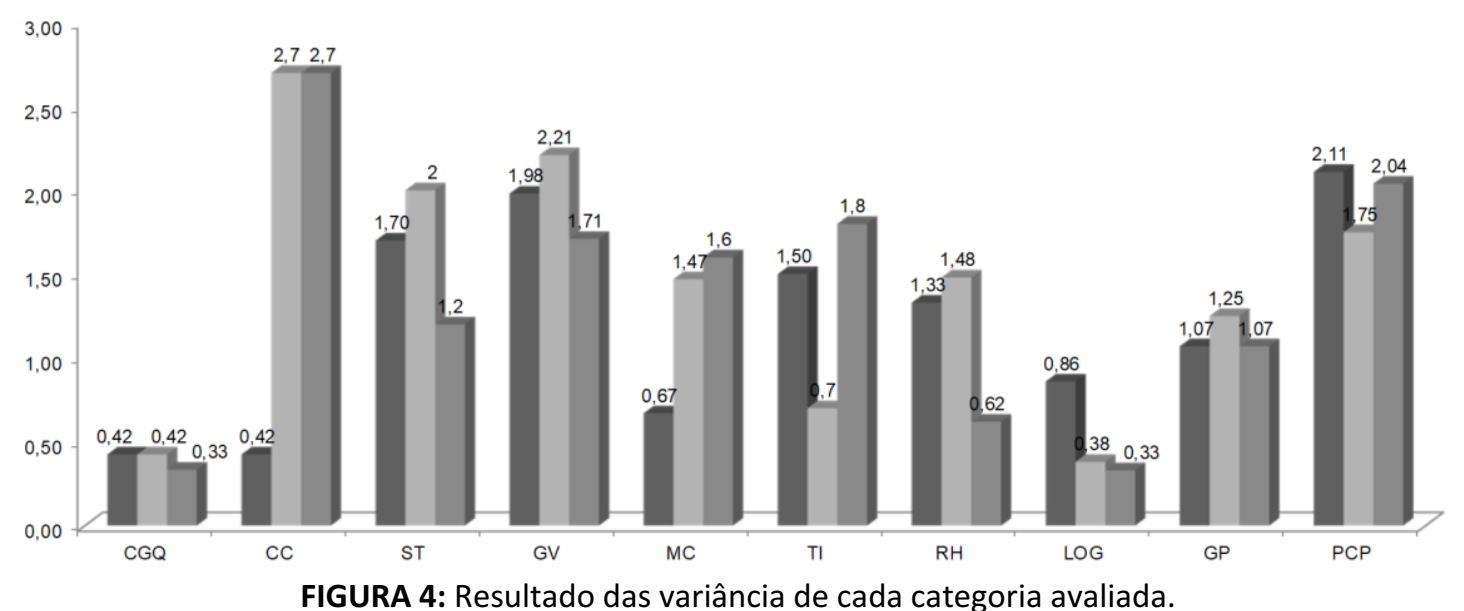

FONTE: Autoria própria.

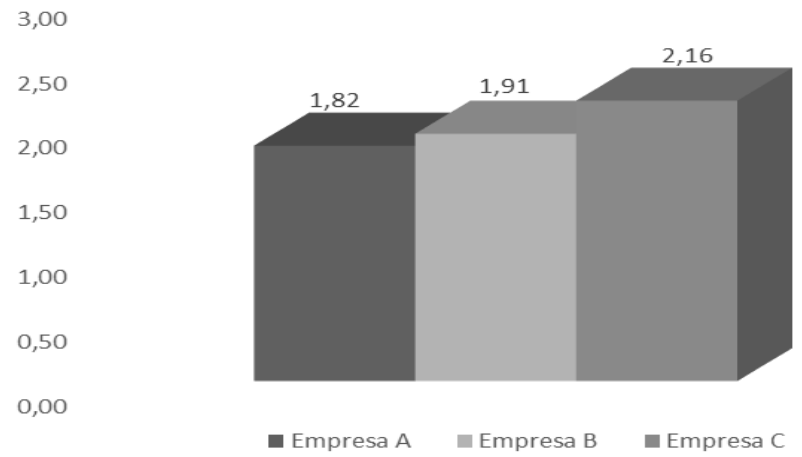

FIGURA 5: Média Global utilizando todas as categorias do questionário.

FONTE: Autoria própria.

$\mathrm{Na}$ análise comparativa das empresas, se observa que a empresa ' $C$ ' apresentou a maior implementação de práticas, de acordo com o questionário aplicado, obtendo o melhor resultado global entre as empresas avaliadas (Figura 5 e 6). 


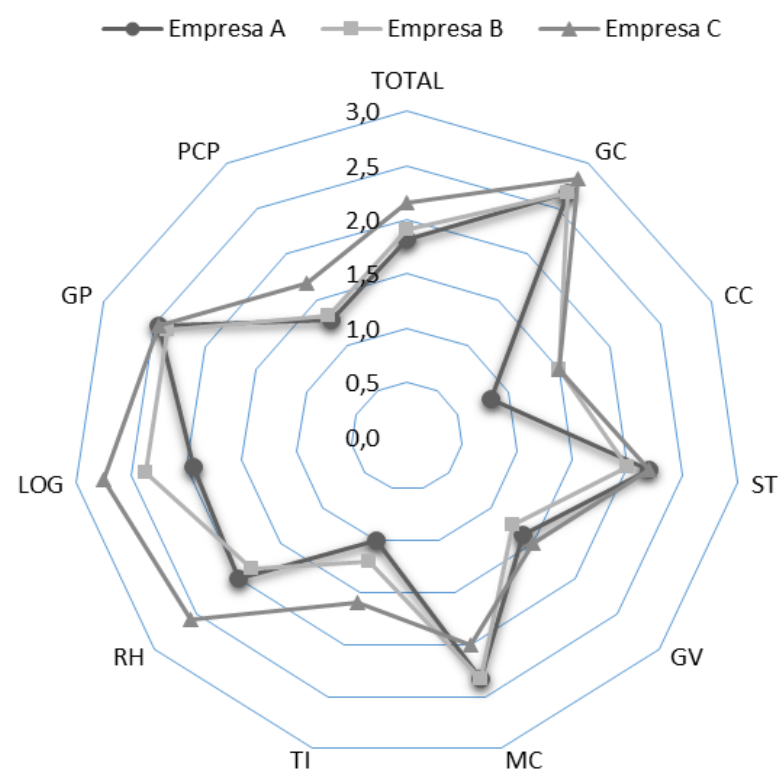

FIGURA 6: Análise comparativa das três empresas por categoria. FONTE: Autoria própria.

\subsection{DISCUSSÃO POR CATEGORIAS AVALIADAS}

\subsubsection{Gestão da Qualidade}

A primeira das categorias avaliadas no questionário, Gestão da Qualidade, possui doze práticas e foi a que obteve o melhor resultado em todas as empresas participantes da pesquisa, obtendo as melhores médias entre todas as categorias e não recebendo nota $0 \mathrm{em}$ nenhuma prática. Sua utilização é relacionada a conceitos como padronização do trabalho, treinamento de funcionários, utilização de poka-yokes e controle de qualidade. A existência de uma boa gestão nessa área já era esperada nos resultados, pois está diretamente relacionada a existência de um Sistema de Gestão da Qualidade implementado, e as notas maiores desta categoria estão ligadas ao fato de suas práticas também serem relacionadas às normas de qualidade.

Como ilustrado na Figura 3, as empresas mostraram resultados semelhantes. A empresa ' $C$ ', no entanto, obteve valores ligeiramente superiores quanto à média, o que denota uma qualidade um pouco melhor. Apenas em uma das práticas da categoria, relacionada a dispositivos visuais onde há não conformidades, a empresa ' $C$ ' não obteve nota máxima.

\subsubsection{Controle de Custos}

Nesta categoria, que faz uma análise dos custos, o número de práticas avaliadas foi metade da anterior (06 práticas). Os quesitos avaliados foram basicamente a monetarização das perdas envolvidas, metas de redução de custos e definição de custo alvo.

A empresa ' $A$ ' recebeu, nesta categoria, os piores resultados dentre as empresas avaliadas e entre as categorias do questionário, com média de aproximadamente a metade das outras, apresentando outros dados estatísticos também baixos, mostrando a frequência alta de notas baixas recebidas.

Embora apresentassem resultados melhores que a empresa ' $A$ ', as outras duas empresas não obtiveram notas altas em comparação com a categoria anterior, com média de apenas 1,5.

Esta categoria é extremamente importante na Construção Enxuta, pois trata da identificação de perdas no processo construtivo e seus respectivos custos gerados. Seu resultado insatisfatório se deve em parte à sua aplicação ser uma etapa bem específica do pensamento lean e de sua implementação, denotando falta de conhecimento sobre o processo por parte da 
administração ou aplicação sem rigor das práticas em questão.

\subsubsection{Segurança do Trabalho}

Na Segurança do Trabalho, as empresas receberam nota máxima em três das cinco práticas analisadas, que consideravam planejamento, análises de risco e treinamento das equipes. Nas outras duas práticas, sobre realização de Diálogo Diário de Segurança (DDS) e indicadores de Saúde e Segurança do Trabalho, as notas não foram satisfatórias, diminuindo a média geral da categoria. As empresas ' $A$ ' e ' $C$ ' obtiveram média de 2,2. A empresa ' $B$ ' ficou próxima às duas, com média de 2,0.

As boas notas obtidas refletem mais a preocupação das empresas em atender a legislação de segurança atual e da fiscalização na área, que aplica severas multas ao descumprimento das normas de segurança no trabalho, do que, necessariamente, um planejamento das empresas em implementar conceitos enxutos relacionados a este item. As notas baixas na terceira prática desta categoria reforçam a situação mencionada, pois esta diz respeito a existência de DDS, que é uma prática que, apesar de importante, não consta na norma e é muitas vezes deixada de lado em vários canteiros de obra ('A' e 'B' não realizam, por isso receberam 0 ).

\subsubsection{Gerenciamento Visual}

Nessa categoria, as oito práticas avaliadas dizem respeito a organização do ambiente de trabalho e a disposição das informações da obra no canteiro. Novamente, as notas atribuídas foram contrastantes entre cada prática, com as empresas recebendo notas máximas em algumas e notas 0 ou 1 nas restantes. As médias obtidas foram bem próximas, 1,4 para ' $A$ ', 1,3 para ' $B$ ' e 1,5 para ' $C$ '.

$A$ empresa ' $B$ ' apresentou os piores resultados, com variância bem maior que as outras e sendo a única a obter mais notas 0 do que 3 nesta categoria. A empresa ' $C$ ' merece destaque, pois foi a única a apresentar quadro visível a todos os funcionários, com informações diversas, assim como de planejamento, recebendo nota máxima neste quesito. Porém, apesar de ter os melhores resultados em Gerenciamento Visual, a empresa ' $C$ ' foi mal avaliada em seus dispositivos visuais relativos a categoria de Gestão de Qualidade, como citado anteriormente, e foi a única que não possuía em seu canteiro dispositivos visuais com orientações para execução de tarefas. Em comparação, a empresa possui mais práticas com nota 1 em constrate com as 0 recebidas pelas outras, o que demonstra um maior conhecimento e vontade de aplicação da Construção Enxuta, condizendo com o que foi dito pela empresa durante as entrevistas de aplicação do questionário.

Este item do questionário é importante para o lean, pois também diz respeito ao gerenciamento da informação, buscando a transparência das etapas do processo produtivo para todos os colaboradores e auxilia no fluxo de valor das atividades.

\subsubsection{Melhoria Contínua}

A melhoria contínua está diretamente ligada ao princípio enxuto de Perfeição e é essencial a qualquer tentativa de aplicação da Construção Enxuta. No questionário, foi avaliada a busca por inovações tecnológicas e métodos de soluções de problemas, incluindo o uso do ciclo de Deming PDCA (plan, do, check e act) e benchmarking entre os empreendimentos da própria empresa, totalizando seis práticas.

Em relação aos resultados, todas as empresas conseguiram boas avaliações nessa categoria. No entanto, a empresa ' $A$ ' foi bastante consistente, recebendo boas notas em todas as seis práticas, principalmente nas que envolviam soluções de problemas.

Também vale ressaltar que as empresas 'B' e 'C' obtiveram uma nota 0 . A primeira por não possuir um grupo de solução de problemas e a segunda por não ter banco de dados de melhores práticas desenvolvidas no canteiro de obra.

As boas notas, em geral, mostram o entendimento que as empresas têm sobre a importância da Melhoria Contínua no processo de construção e sobre seus benefícios. Em contrapartida, a média obtida $e$ as notas 0 demonstram que ainda existe espaço para melhora 
nesta categoria e que, embora haja entendimento, ainda há muito o que evoluir na aplicação deste princípio por parte das empresas.

\subsubsection{Tecnologia da Informação e Comunicação}

O número de práticas avaliada neste item, juntamente com Segurança do Trabalho, é o mais reduzido do questionário, com apenas cinco. Foram avaliados a utilização de softwares e ferramentas de controle em tempo real no canteiro de obras e os meios de comunicação disponíveis para os funcionários.

Com médias baixas, essa categoria se destacou negativamente. Apenas o item de meios de comunicações e informação para funcionários foi bem avaliado nas empresas. A empresa ' $A$ ', com uma média de apenas 1,0, foi a pior entre as empresas, seguida por ' $B$ ', com 1,2. Já a empresa ' $C$ ' alcançou uma média um pouco superior, de 1,6, pois conseguiu duas notas máximas, em utilização de softwares avançados, além da comunicação entre os trabalhadores. As três empresas ficaram abaixo das expectativas nas três primeiras práticas, por não utilizar ferramentas de controle em tempo real.

As práticas, mais uma vez, dizem respeito a itens bem específicos da Construção Enxuta, relativos a produção, qualidade e estoque. Neste contexto, se repetem as notas baixas de outras práticas com o mesmo quesito. Assim como em Controle de Custos, a falta de conhecimento e visão sobre os reais benefícios que podem ser atingidos atrapalha a organização da empresa. 0 uso das ferramentas, cujo item avalia, beneficia o controle do canteiro de obras, melhora a eficiência dos trabalhadores envolvidos e dos processos em andamento. As notas 1 recebidas nessas três primeiras práticas ajudam a corroborar esse exemplo e evidenciam que as empresas conhecem os métodos a serem empregados, mas não tem planos iminentes para sua aplicação.

\subsubsection{Recursos Humanos}

Em Recursos Humanos, com sete itens, é avaliada a existência de práticas voltadas ao desenvolvimento do funcionário, com políticas motivacionais, promoção de multifuncionalidade, avaliação de desempenho e feedback dos resultados. Também é observado se há incentivos a atividades externas ao trabalho em si, seja de cultura, lazer ou educação.

Até este ponto, as médias apresentadas neste item contêm a maior diferença entre duas empresas, juntamente com Controle de Custos. Entretanto, a situação que ocorre neste caso é o contrário do observado anteriormente, com uma empresa obtendo valores maiores de média em comparação com as outras duas com resultados semelhantes (a maior de 2,6 para ' $C$ ', e a menor de 1,9 para ' $B$ '). Para obter essa média, a empresa ' $C$ ' recebeu nota máxima em cinco das sete práticas contidas na categoria, sendo a única a receber nota máxima em políticas motivacionais. Suas únicas falhas foram em relação ao desenvolvimento de funcionários multifuncionais, que não são muito estimulados, e no feedback da avaliação de desempenho aos funcionários, que recebeu nota 2 , o que demonstra que embora existam defeitos neste quesito, a empresa segue no rumo certo para sua aplicação com maior eficácia.

As empresas ' $A$ ' e ' $B$ ', embora não apresentem resultados satisfatórios como ' $C$ ', ainda conseguiram boas médias em comparação com os resultados de outras categorias e muito parecidos entre si. Estes valores demonstram que no geral as empresas dão atenção a questões relacionadas a recursos humanos, embora ainda falte iniciativa para a elaboração de políticas motivacionais. Uma prática que é bem específica da produção enxuta é a multifuncionalidade, ou polivalência funcional, que torna o funcionário mais autônomo e consciente do seu trabalho no resultado global da obra, e sua nota baixa em todas as empresas demonstra que ainda falta treinamento neste quesito para se atingir níveis enxutos maiores para esta categoria.

\subsubsection{Logística e Gerenciamento da Cadeia de Suplementos}

Esta categoria é a segunda maior em relação a quantidade de práticas, com 16. Nela avaliou-se a preocupação que as empresas tinham com relação ao fornecimento, armazenamento, controle e distribuição dos suprimentos durante 
sua cadeia produtiva. Levou-se em consideração praticas de controle de estoque, qualificação e parcerias de fornecedores, estudo do layout do canteiro de obra e distribuição interna de suplementos.

A empresa ' $C$ ' obteve melhor desempenho que as demais principalmente pelo fato de trabalharem com canteiro confinado, sendo necessária a busca por fornecedores que trabalham com o fornecimento Just in Time (JIT), reduzindo a quantidade de materiais presentes nos estoques ao longo das etapas de processamento. Mas em âmbito geral, notou-se um bom desempenho de todas as empresas neste item.

Grande parte das práticas obtiveram notas máximas. Parte desse bom desempenho decorre de várias práticas já serem obrigatórias para a obtenção do certificado da Qualidade ISO 9001, porém, alguns itens específicos da construção enxuta, não foram aplicados por nenhuma empresa participante, a exemplo dos que citam a utilização de ferramentas como andos e kanbans no controle de distribuição de suprimentos.

\subsubsection{Gerenciamento de Projetos e Desenvolvimento de Produtos}

A maioria das 11 práticas avaliadas nessa categoria, estão vinculadas aos princípios de fluxo contínuo ou à cadeia de valores. Esta foi umas das categorias que obtiveram um bom desempenho. Esse fato é proveniente da preocupação das empresas em avaliar as necessidades do cliente buscando uma identificação do valor requerido pelo mesmo antes do desenvolvimento do produto, a fim de agregar valor e adequar o produto final ao mercado.

As etapas de coordenação no desenvolvimento dos projetos nas empresas ' $A$ ' $\mathrm{e}$ ' $C$ ' são terceirizadas, obtendo-se um feedback da empresa terceirizada. Apesar de a empresa 'B' apresentar um controle interno, isso não chega a afetar os resultados obtidos. Como pode ser observado na Figura 3, as empresas apresentam notas semelhantes.
Notou-se a falta do controle rígido no processo de planejamento e desenvolvimento de projetos e novos produtos, principalmente a inexistência de cronogramas de médio e curto prazo para a criação do projeto, e a não apresentação de um check-list de qualidade e compatibilidade para revisão do projeto antes da sua execução no canteiro.

\subsubsection{Planejamento e Controle da Produção}

Com 22 práticas, a última categoria é a maior em quantidade de práticas, englobando todos os 5 princípios da produção enxuta citados no trabalho de Womack e Jones (1998). Nas práticas relacionadas ao planejamento da produção, avaliou-se o planejamento de curto, médio e longo prazo, buscando a identificação da remoção sistemática das restrições das frentes de serviços, a predefinição de tarefas suplentes e o mapeamento das atividades que agregam valor. Quanto ao Controle da Produção, as práticas, buscaram a padronização do trabalho e a utilização de indicadores que auxiliam e facilitam o monitoramento e análise da produção, a exemplo dos Gráficos de Balanceamento de Operações (GBO).

Ao se avaliar o planejamento de longo, médio e curto prazo, todas as empresas obtiveram êxito, mas ao analisar a remoção sistemática de restrições, definições de tarefas suplentes, mapeamento de valor e outras práticas de grande relevância na Construção Enxuta, as empresas avaliadas não obtiveram boas notas, dando a entender que o desempenho obtido nesta categoria foi oriundo do cumprimento de práticas gerais de planejamento e controle da produção, que não são exclusivas ao pensamento enxuto.

Esse agravante pode ser relacionado com a falta de implantação de ferramentas para auxiliar o controle do processo de produção e análise de produtividade. Não se observou, em nenhuma empresa, estratégias para a utilização do tempo takt para a sincronização da produção, nem mesmo para reduzir as parcelas que não agregam valor no trabalho em processo. 


\section{CONCLUSÃO}

Conclui-se que as três construtoras avaliadas apresentam um bom desempenho de acordo com a ferramenta de Camargo Filho (2017). Percebe-se que os Sistemas de Gestão da Qualidade já implementados tiveram grande influência no bom desempenho das construtoras, principalmente nas categorias de Gestão da Qualidade, Melhoria Contínua e Logística e Gerenciamento da Cadeia de Suprimentos.

Na categoria de Segurança do Trabalho, boa parte das práticas são englobadas pela legislação brasileira, com isso os itens que obtiveram nota 3 , em sua maioria, são previstos nas fiscalizações e passiveis de autuação, caso ocorra o seu descumprimento. Diante do exposto, se conclui que a ferramenta utilizada para diagnosticar o grau de implantação precisa passar por reformulações para obter um resultado mais conclusivo dos reais níveis de aplicação lean nas construtoras, dando maior ênfase nas ferramentas lean. Além disso, algumas práticas ainda são subjetivas e dependem da opinião do aplicador para atribuição da nota.

Contudo, a ferramenta proposta se tornou eficaz ao analisar quais déficits, cada empresa têm na implementação da Construção Enxuta em seu processo produtivo. Destacam-se as práticas das categorias de Gestão de Custo, Gerenciamento Visual, Tecnologia da Informação e Planejamento e Controle da Produção pelo seu desempenho negativo, como discutido anteriormente, justificado pelo fato de conterem uma quantidade maior de itens específicos.

Quanto à implementação da Construção Enxuta nas três empresas, se observa que seus bons resultados são decorrentes de seus Sistemas de Gestão da Qualidade já consolidados e da difusão de boas práticas desenvolvidas nas empresas por meio da participação nos encontros propostos pela Comunidade da Construção.

\section{REFERÊNCIAS BIBLIOGRÁFICAS}

BALLARD, G. HOWELL, G. Toward construction JIT. $11^{\text {th }}$ Annual Association of Researchers in Construction Management Conference, Proceedings, Loughborough, 1995.

BARROS, E. S. Aplicação da construção enxuta no setor de edificações: Um estudo multicaso. Dissertação apresentada ao Programa de Pós-Graduação em Engenharia de Produção, Universidade Federal de Pernambuco, Recife, 2005.

CAMARGO FILHO, C. A. B. LCAT: Ferramenta de avaliação da implementação da Construção Enxuta. Mestrado apresentado ao Programa de Pós-Graduação em Geotecnia, Estruturas e Construção Civil, Universidade Federal de Goiás, Goiânia, 2017.

CARVALHO, B. S. Proposta de uma ferramenta de análise e avaliação das construtoras em relação ao uso da construção enxuta. 2008. 141 f. Tese (Mestrado em Engenharia Civil) - Setor de Tecnologia, Universidade Federal do Paraná, Curitiba, 2008.

CBIC - CÂMARA BRASILEIRA DA INDÚSTRIA DA CONSTRUÇÃO. Sondagem Indústria da Construção. Ano 7, Número 3, Publicação Online, 2016.

ETGES, B. M. B. S. Protocolo de auditoria do uso de práticas da construção enxuta. 2012. 85 f. Tese (Mestrado em Engenharia da Produção) - Escola de Engenharia Civil, Universidade Federal do Rio Grande do Sul, Porto Alegre, 2012.

FORMOSO, C. T. Lean Construction - Princípios básicos e exemplos. Apostila sobre Lean Construction - UFRGS - Escola de Engenharia - NORIE - Porto Alegre, 2002.

HOWELL, G. A. What is lean construction. In: Seventh Conference of the International Group for Lean Construction, 1999, University of Berkeley, California, EUA. Proceedings IGLC -7, p 1-10.

JUNQUEIRA, L. E. L. Aplicação da lean Construction para redução dos custos de produção da casa $1.0^{\oplus}$; São Paulo, 2006. 146p. Dissertação (Especialização) Escola Politécnica da Universidade de São Paulo. Departamento de Engenharia de Produção.

KOSKELA, L. Application of the new production philosophy to construction. Stanford Center for Facility Engineering, TECHNICAL REPORT 72, 1992, 75p.

KOSKELA L. An exploration towards a production theory and its application to construction. Dissertation for the degree of Doctor of Technology at Helsinki University of Technology - Espoo: Technical Research Centre of Finland. Finlad, 2000. 
SOARES C. TOC, STP e TQC: Uma abordagem conjunta. ENEGEP. - Niteroi- RJ, 1998.
WOMACK, J.P.; JONES, D.R. A Mentalidade Enxuta nas Empresas: Elimine o desperdício e crie riquezas. 5. ed. Rio de Janeiro: Campus, 1998. 